\title{
Test and analysis of electric arc machining characteristics of high-temperature alloy materials
}

\author{
Hai Peng ${ }^{1, a}$ Xuliang Pan ${ }^{2, b}$ \\ ${ }^{1.2}$ School of Mechanical Engineering, Xi'an Shiyou University, Xi'an, Shannxi (710065), China \\ ahpeng1104@sina.com, b519374278@qq.com
}

\begin{abstract}
Keyword: High-temperature alloy; Electric arc machining; Electrical machining parameters.
Abstract. Short electric arc machining is a new type of non-contact strong current machining, it has the charactristics of no cutting force, simple electrode manufacturing, high processing efficiency, etc. In order to study the machining properties of Ni-base high-temperature alloy materials,the mechanical machining properties and the arc machining characteristics of Ni-base high-temperature alloy materials are analyzed theoretically and the corresponding short arc machining mechanism is determined, then it uses that orthogonal test to carry out short arc machining experiment on Ni-base high-temperature alloy and determines the primary factor and optimal electrical machining parameter which affect the quality of the machined surface. The result shows that the lower the discharge voltage, the better the surface quality of the processed materials under the same electrical parameters. The factors that affect the surface quality of the workpiece are the power supply voltage > discharge gap > spindle speed and the best electrical machining parameters are $0.5 \mathrm{~mm}$ in discharge gap, 60r/min in spindle speed and $10 \mathrm{~V}$ in power voltage. At the same time, thermal impact analysis is carried out by using infrared thermography and surface heat affected layer after processing is tested and analyzed. Finally, the change rule of metallographic structure, hardness and heat affected layer of it after arc machining are determined. Experiments show that the strength and hardness are improved and the matrix structure of crystal is less affected by heat, metallographic structure has no obvious change and it can get a better surface quality, which provides a theoretical basis for high-temperature alloy materials for arc machining.
\end{abstract}

\section{Introduction}

Ni-base high-temperature alloy based on nickel substrate (content is generally greater than 50\%), within the range of $650 \sim 1000^{\circ} \mathrm{C}$ with high strength and good resistance to oxidation and gas corrosion resistance of high-temperature alloy[1]. With the development of modern science and technology, Ni-base high-temperature alloy is widely used in aviation, aerospace, petroleum, chemical industry and used to make aviation jet engine, turbine disk, etc[2]. However, it is a typical hard-to-machine material and its machinability is poor, mainly reflected in the high cutting temperature, large cutting force, serious tool wear, serious work hardening and low accuracy of machining, especially in the area of deep hole machining difficulty, while nesting processing cannot be achieved. Short electric arc machining is a kind of non-contact strong current machining, its processing performance of the workpiece material mainly depends on the physical properties of material, instead of traditional machining in mechanical properties such as strength, toughness and stiffness. It has the characteristics of no cutting force, simple electrode manufacturing, high machining efficiency and low working noise, etc. Therefore, the study of short electric arc machining characteristics of high-temperature alloy materials has a certain guiding significance for short electric arc machining technology.

\section{Analysis of mechanical machining properties and electric arc machining characteristics of Ni-base high-temperature alloy}

Ni-base high-temperature alloy in high temperature environment, not only has characteristics of high strength, high hardness, oxidation resistance and corrosion resistance, but also has properties of good thermal stability and thermal fatigue resistance, etc. Its high temperature strength and thermal stability produce a great cutting force in the cutting process, which makes serious tool wear 
and reduce tool life. At the same time, because of its poor thermal conductivity, during the cutting process, a large amount of cutting heat is not easy to disperse, resulting in high cutting temperature. Reinforcement phase of Ni-base high-temperature alloy is easily decomposed under the high temperature cutting condition, and will be distributed on the surface of the organization after decomposition, thus, it can result in serious hardening of the machining surface. In addition, due to the tool wear quickly, so that the built-up edge of workpiece surface and debris deposition is increased, eventually the processing accuracy of workpiece is decreased[3].

In the process of short electric arc machining, the arc machining characteristics of materials are not affected by their mechanical properties, but mainly depend on the thermal physical properties. The thermal physical properties of materials mainly include melting point, thermal conductivity, density and specific heat capacity, etc. Ni-base high-temperature alloy material tested in this paper is In625 and its thermal physical properties are shown in table 1. As can be seen from the table, the specific heat capacity of In625 is larger and the energy absorption capacity is stronger, furthermore, the surface metal material is not easily melted in the heat produced by processing, so the removal rate of the material will be reduced in the arc processing. The thermal conductivity of In 625 is smaller, the heat received on the surface of the workpiece will not rapidly diffuse into the interior of the material, and its internal tissue performance is not affected greatly, thus the surface heat affected layer formed in the arc machining is small. In625 has a greater density than other hard-to-machine materials such as titanium alloy and stainless steel, so its own compactness is bigger. Under the high temperature generated by arc discharge, the gas expands instantly and explodes, the melted metal with large compactness is not easy to out of the workpiece surface under the explosive force, the material removal rate decreases, so the surface quality is relatively good.

Tab. 1 Ni-base high-temperature alloy（In625） thermal physical properties

\begin{tabular}{cccccc}
\hline material & $\begin{array}{c}\text { Density } \rho \\
\left(\mathrm{g} / \mathrm{cm}^{3}\right)\end{array}$ & $\begin{array}{c}\text { Melting } \\
\text { point } \\
\left({ }^{\circ} \mathrm{C}\right)\end{array}$ & $\begin{array}{c}\text { Thermal } \\
\text { Conductivity } \\
\lambda\end{array}$ & $\begin{array}{c}\text { Specific heat } \\
\text { capacity c } \\
\left(\mathrm{W} / \mathrm{m} \bullet{ }^{\circ} \mathrm{C}\right)\end{array}$ & $\begin{array}{c}\text { Resistivity } \\
\left(\mathrm{J} / \mathrm{kg} \bullet{ }^{\circ} \mathrm{C}\right)\end{array}$ \\
\hline In625 & 8.4 & 1350 & 19.7 & 762 & 1.29 \\
\hline
\end{tabular}

\section{Analysis of short electric arc processing principle and discharge mechanism}

The short electric arc machining system is mainly composed of the main body of the machine, short electric arc power supply, anode and cathode device, tool electrode, machined workpiece and working medium. The principle of short electric arc machining is shown in figure 1. Using the tool electrode and processed workpiece as the discharge electrode. The tool electrode is fixed on the cathode device and connected to negative pole of short electric arc power supply, and the processed workpiece is fixed on the anode device and connected to positive pole of short electric arc power supply. Meanwhile, the tool electrode and the processed workpiece should be kept a certain gap and both must be taken insulation measures. During machining, a discharge channel is formed between the tool electrode and the workpiece surface to form a strong electronic current. The high temperature and spark generated by the discharge channel make the material to be partially melted and vaporized. In the working medium, the high pressure produced by expansion of high temperature causes metal of the workpiece surface to melt rapidly and peel off the workpiece to achieve the purpose of removing the surface of material[4].

When short arc pulse power supply is applied between the tool electrode and the workpiece, an electric field is immediately formed between two poles. The discharge occurs when the intensity of the electric field first reaches the intensity value that required for discharge between gaps. A certain proportion of working medium with pressure contains a large amount of impurities and conductive microscopic particles, and they make the electric field unevenly distribute. As distance between the poles decreases, somewhere in the electric field increase enough to discharge and it will launch field-induced electrons. Field-induced electrons move from the cathode to the anode and can be 
accelerated in the electric field. After getting a high enough speed, the field-induced electrons are colliding with the microscopic particles of the poles, which makes the microscopic particles have a lot of energy, thus, the high energy content of the poles increases exponentially. These microscopic particles reach the anode and then cause the working medium to be punctured and the discharge channel is formed. When the no-load voltage drops to a stable operating voltage, the microscopic particles in the discharge channel collide with each other and gain tremendous energy and speed, and the energy of microscopic particles changes from electrical energy to kinetic energy and then into thermal energy. The two poles of the discharge channel become transient heat sources and reach a high temperature. Under this temperature, A certain proportion of working medium is vaporized, and the material of the workpiece is melted and vaporized. In the end, the surface is etched away, thus completing the arc machining process[5].

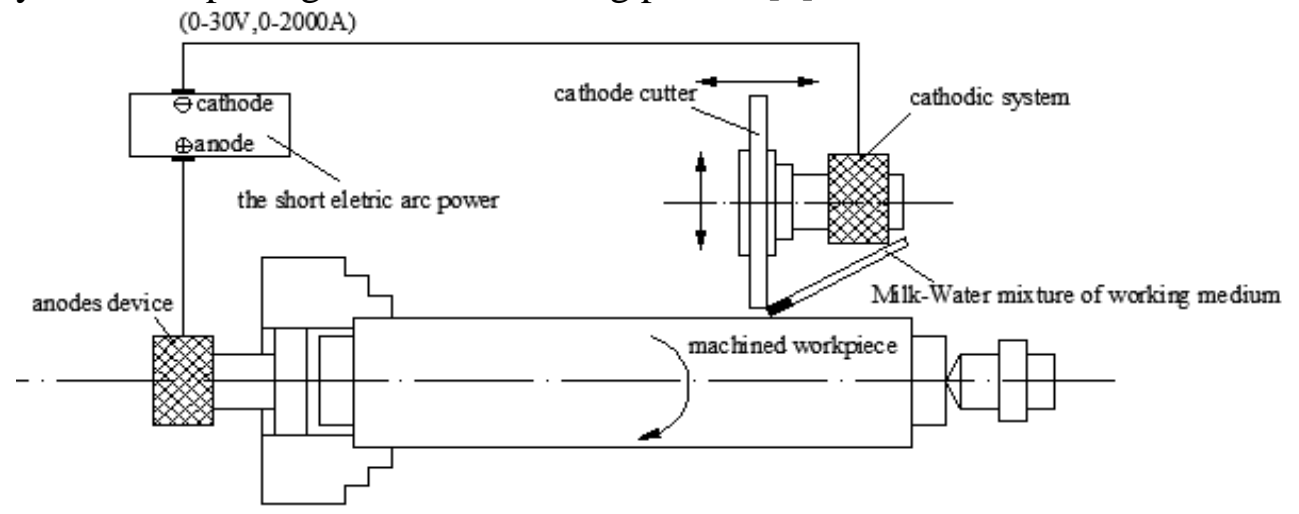

Fig 1 The principle of short electric arc machining

\section{Test and analysis of electric arc machining of Ni-base high-temperature alloy}

The test and analysis of electric arc machining of Ni-base high-temperature alloy by orthogonal design method. The purpose of the experiment is to study the influence of electrical machining parameters on the arc machining characteristics of Ni-base high-temperature alloy (In625). Furthermore, the hardness and metallographic structure of the surface heat affected layer of material are tested and analyzed. Then determine the law of change. The processing power supply used in the experiment is DHX33A3000/28FS short electric arc cutting power supply, whose working current is up to $2000 \mathrm{~A}$, and the voltage range is $0 \sim 30 \mathrm{~V}$. The material of tool electrode is made of 45 steel as a cutter head, and it is $675 \mathrm{~mm}$ in diameter and $12 \mathrm{~mm}$ in thickness. The sample material is In625, which size is $\phi 40 \mathrm{~mm} \times 110 \mathrm{~mm}$. The working medium chooses emulsion with a certain pressure.

Multi-factor orthogonal test of In625 for short electric arc machining. The effect of discharge gap, spindle speed and power supply voltage on short arc machining characteristics of In625 are studied by orthogonal experiment. The primary and secondary factors and optimal electrical machining parameter are determined which affect the quality of the machined surface in the process of short arc machining. The factor-level table of orthogonal test is shown in table 2.

Tab.2 Factor-level table of orthogonal test for short electric arc machining of In625

\begin{tabular}{cccc}
\hline & \multicolumn{3}{c}{ Factor } \\
\cline { 2 - 4 } Level & $\begin{array}{c}\text { A Discharge gap } \\
(\mathrm{mm})\end{array}$ & $\begin{array}{c}\text { B Spindle speed } \\
(\mathrm{r} / \mathrm{min})\end{array}$ & C voltage $(\mathrm{V})$ \\
\hline 1 & $0.5(\mathrm{~A} 1)$ & $24(\mathrm{~B} 1)$ & $10(\mathrm{C} 1)$ \\
2 & $0.3(\mathrm{~A} 2)$ & $60(\mathrm{~B} 2)$ & $15(\mathrm{C} 2)$ \\
3 & $0.1(\mathrm{~A} 3)$ & $118(\mathrm{~B} 3)$ & $20(\mathrm{C} 3)$ \\
\hline
\end{tabular}

Nine groups of experiments are determined according to 3 factors and 3 levels and experiments are analyzed in extreme differences. Based on this, the influence of several factors on the 
experiment is obtained. The orthogonal experimental results are shown in table 3.

Tab.3 Results of orthogonal test for electric arc machining of In625

\begin{tabular}{|c|c|c|c|c|c|}
\hline \multirow[b]{2}{*}{ project } & A & $\mathrm{B}$ & $\mathrm{C}$ & \multirow[b]{2}{*}{$\begin{array}{c}\text { Discharge } \\
\text { current (A) }\end{array}$} & \multirow{2}{*}{$\begin{array}{l}\text { Test results } \\
\text { Surface } \\
\text { roughness }(\mu \mathrm{m})\end{array}$} \\
\hline & $\begin{array}{l}\text { Discharge } \\
\text { gap (mm) }\end{array}$ & $\begin{array}{l}\text { Spindle speed } \\
(\mathrm{r} / \mathrm{min})\end{array}$ & $\begin{array}{l}\text { Voltage } \\
\text { (V) }\end{array}$ & & \\
\hline 1 & 0.5 & 24 & 10 & 200 & 53.64 \\
\hline 2 & 0.5 & 60 & 15 & 380 & 61.78 \\
\hline 3 & 0.5 & 118 & 20 & 630 & 65.24 \\
\hline 4 & 0.3 & 60 & 20 & 800 & 69.77 \\
\hline 5 & 0.3 & 118 & 10 & 350 & 49.64 \\
\hline 6 & 0.3 & 24 & 15 & 390 & 63.23 \\
\hline 7 & 0.1 & 24 & 15 & 480 & 70.54 \\
\hline 8 & 0.1 & 118 & 20 & 860 & 73.27 \\
\hline 9 & 0.1 & 60 & 10 & 380 & 51.76 \\
\hline $\bar{K}_{1}$ & 60.22 & 62.47 & 51.68 & 64.65 & \\
\hline $\bar{K}_{2}$ & 60.88 & 61.10 & 65.18 & 61.56 & \\
\hline $\bar{K}_{3}$ & 65.19 & 62.72 & 69.43 & 60.08 & \\
\hline $\mathrm{R}$ & 4.97 & 1.62 & 17.72 & 4.48 & \\
\hline
\end{tabular}

Through the above experimental data analysis, the primary and secondary order of factors which affect the roughness of the machining surface are obtained and that is power supply voltage $\mathrm{C}>$ discharge gap A > spindle speed B. The experimental results show that the higher the power supply voltage, the higher the discharge process and the amount of heat produced is increased, which makes the surface quality worse after processing. The larger the discharge gap, the intensity of electric field decreases, and the intensity of discharge decreases, which makes the machining surface quality better. The proper spindle speed will makes the discharge channel more uniform and reduces the heat absorbed of the same point, thus improves the surface quality. Therefore, the optimal processing scheme is $\mathrm{A}_{1} \mathrm{~B}_{2} \mathrm{C}_{1}$, which is $0.5 \mathrm{~mm}$ in discharge gap, $60 \mathrm{r} / \mathrm{min}$ in spindle speed and $10 \mathrm{~V}$ in power supply voltage.

Effect of power supply voltage on surface quality of In625. The power supply voltage as the electrical machining parameter has a great impact on the surface roughness of the material for electric arc machining. In order to determine the effect of Ni-base high-temperature alloy on the surface quality under different voltages, two kinds of materials are used respectively to analyze the change rule in the surface properties of the material under three different power parameters. Therefore, the arc processing experiments of In625 and stainless steel PH17-4 are conducted respectively in the case of other parameters unchanged, only the discharge voltage is changed. The surface characteristics of the workpiece after processing are shown in figure 2 . The three processing surfaces in the figure from left to right in turn to $10 \mathrm{~V}, 15 \mathrm{~V}$ and $20 \mathrm{~V}$ discharge voltage.

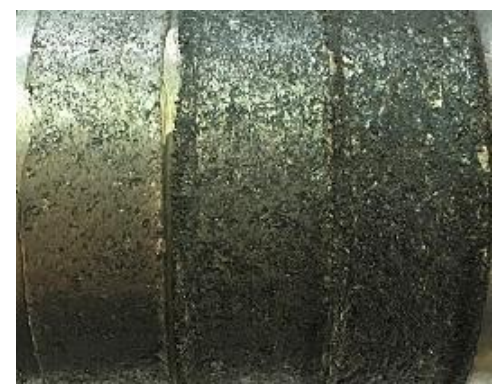

In625

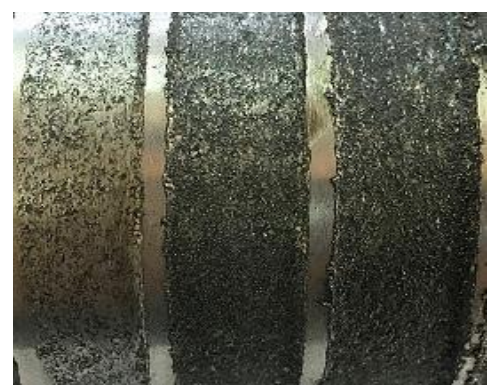

PH17-4

Fig 2 The machining surface characteristics of In625 and PH17-4 under different voltage

We can see from the figure, in the process of electric arc machining, the magnitude of the power 
supply voltage has a great impact on the formation of the surface morphology of the workpiece. When the discharge voltage is $20 \mathrm{~V}$, the machining surface of the workpiece is the roughest. The larger the discharge voltage, the greater the heat in the discharge channel. Furthermore, the area of the workpiece in contact with the discharge channel increases and the volume of the dissolved material becomes larger, then the larger the depression is left on the surface. However, when the discharge voltage is $10 \mathrm{~V}$, the roughness of machining surface is the smallest.

By contrast the surface morphology of In625 and PH17-4, we can see that the surface quality of In625 is better than PH17-4. There are different surface morphology, formed by two different materials and the main reason is that the thermal physical properties of the materials are different. The thermal conductivity of In625 is less than PH17-4 and the heat affected layer of PH17-4 is larger in the same heat. The specific heat capacity of In625 is larger than the specific heat capacity of PH17-4, so In625 can accept more heat than PH17-4 in the unit mass. In addition, because the high-temperature alloy has good high temperature strength and heat resistance, therefore, in the process of short electric arc machining, the material organization is less affected. Thus, we can obtain a good surface quality.

Thermal effect analysis of short arc machining of In625. Electric arc discharge in short arc process can produce high discharge temperature. Meanwhile, the thermal conductivity of In625 is small, so there will be a lot of heat in the process. But on the other hand, if the workpiece is molten and cannot be cooled and stripped quickly in a high temperature environment, it will bond to the electrode and affect the processing. Therefore, it is very important to control the processing temperature of the "cutting" zone. Infrared thermograph is a device that can receive infrared radiation and convert it into visible images[6]. In this experiment, infrared thermograph FLIR T440 is used for the thermometric analysis in the discharge processing area of electric arc machining. Figure 3 shows that the infrared thermal imaging picture of In625 in the discharge processing area.

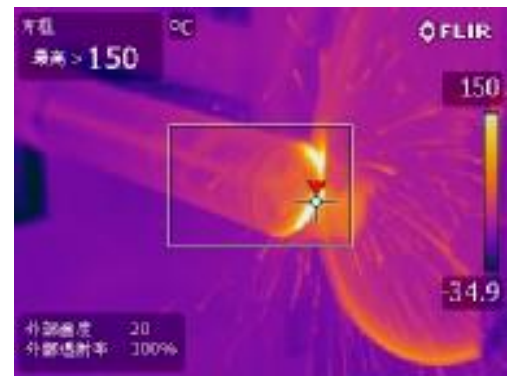

Fig. 3 Infrared thermal imaging picture of In625

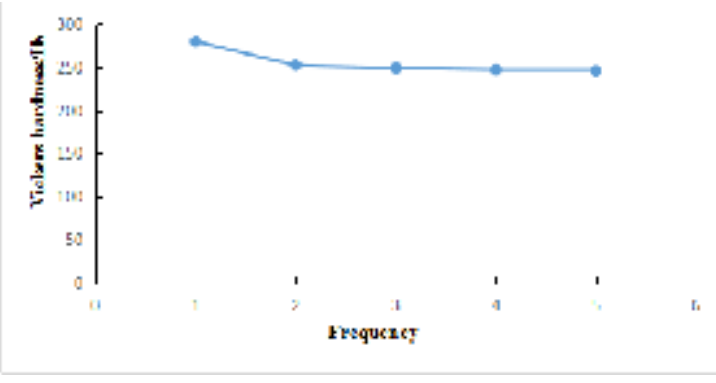

Fig.4 Hardness change of In625

From thermal imaging figure can be seen that point of the highest temperature greater than $150{ }^{\circ} \mathrm{C}$ which the camera captured and the highest temperature in processing area between the workpiece and cutting tool. The color is brightest because the metal around the arc discharge channel melts under the action of the electric energy, but the processed area cools quickly and appears dark red[7]. It is also found that the heat mainly accumulate in the processed region of the workpiece while the temperature on the tool head is much low, so it can be concluded that the removal rate of the machined workpiece is greater than that of the tool head.

Analysis of properties of heat affected layer of In625 in short arc machining. After short electric arc machining, metallic structure of the surface layer of the In625 will occur a certain change, which will also affect the mechanical properties of the material. Therefore, through the detection and analysis of the microstructure of material, it is possible to understand the changes of metallographic structure and hardness of surface. Axio Observer digital material microscope and HXD-1000TMC microhardness tester are used to observe respectively the structure and surface hardness of workpiece before and after processing in this experiment.

Analysis of metallographic structure of machining surface layer. In order to obviously compare the surface changes of material matrix before and after short electric arc machining, the metallographic structure of the material before and after processing is compared.The matrix 
structure of In625 before processing is shown in figure 4. The surface layer structure of In625 after processing is shown in figure 5 .

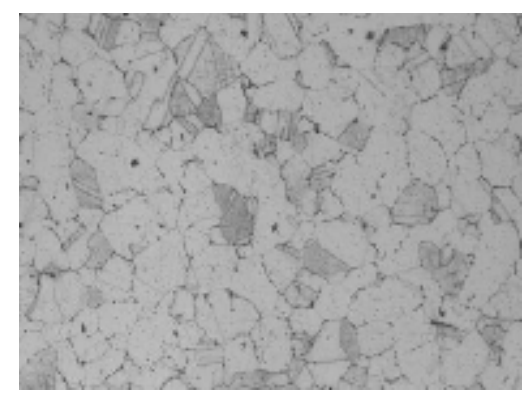

Fig. 5 Matrix structure before processing $(500 \times)$

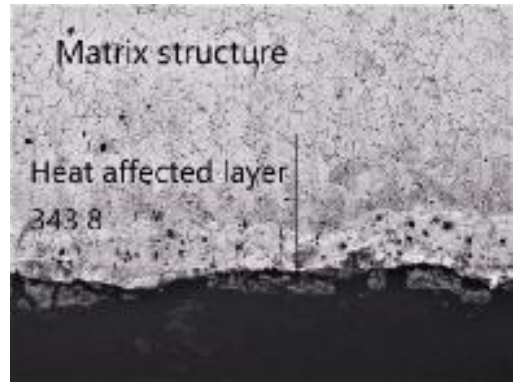

Fig. 6 Matrix structure after processing $(100 \times)$

In625 alloy is a precipitation hardening Ni-base high-temperature alloy. Its metallographic structure consists of $\gamma^{\prime} 、 \gamma^{\prime \prime} 、 \delta 、 N b C$ phase and $\gamma^{\prime \prime}\left(\mathrm{Ni}_{3} \mathrm{Nb}\right)$ is the main strengthening phase. $\gamma$ phase $\left(\mathrm{Ni}_{3}\right)$ work on alloy of auxiliary and reinforcement which organization is spherical diffusion distribution[8]. The heat affected layer thickness of In625 after processing is $343.8 \mu \mathrm{m}$. Because the thermal conductivity of Ni-base high-temperature alloy is low and prevent heat diffusion. Most of the heat is concentrated in the surface layer. Then the structure of surface layer can be fully recrystallized, refined and form a thin and long distributed recast layer organization. Therefore, its strength and hardness is improved, and crystal of the matrix has no significant change under the influence of heat.

Microhardness variation in heat affected layer. The In625 metallographic specimen is measured by five points on the microvickers hardness tester, and the measurement data are shown in figure 6 . Figure 6 shows the change of hardness of the surface layer of In625. It can be seen from the figure that the hardness of the high temperature alloy is not high, but there is a large amount of austenite solid solution with high purity and dense tissue. The lattice distortion of the plastic deformation zone is distorted during short electric arc processing so that the hardness is improved. As the thermal conductivity of In625 is small, the heat in the processing area cannot spread to the interior so as it approaches the matrix, its hardness is stable.

\section{Conclusion}

1. In the process of In625, the surface quality of material is inversely proportional to the discharge voltage. Lower discharge voltage will improves the surface quality of the material. The increase of discharge voltage makes the removal rate of the material increase. Although the processing efficiency is improved, the surface quality of the material is deteriorated. It can be seen from the surface morphology that the surface quality of the material is the best when the voltage is $10 \mathrm{~V}$.

2. Through the result of orthogonal test, the primary and secondary factors which affect the quality of the surface of In625 in the electric arc processing is power supply voltage > discharge gap > spindle speed. The optimal processing scheme is $0.5 \mathrm{~mm}$ in discharge gap, $60 \mathrm{r} / \mathrm{min}$ in spindle speed and $10 \mathrm{~V}$ in power supply voltage.

3. Through the observation of infrared thermal imaging figure, the heat mainly accumulate in the processing area and the highest temperature is greater than $150{ }^{\circ} \mathrm{C}$, but the temperature of the knife plate is low, so the material removal rate of processed workpiece is greater than that of knife plate.

4. After processing, the metallographic structure of In625 has changed, and the heat affected layer thickness of In625 is $343.8 \mu \mathrm{m}$. The structure of surface layer of workpiece can be fully recrystallized, refined and form a thin and long distributed recast layer organization. Therefore, its strength and hardness is improved, and crystal of the matrix has no significant change under the influence of heat. Therefore, it will not have great difficulties for subsequent processing. 


\section{References}

[1] H.Y.Wang, Y.Q.An, C.Y.Li, B.Chao, Y.Ni, G.B. Liu and P.Li:Research Progress of Ni-Base High-Temperature Alloy Materials. Materials Review, Vol.(2011), No.25(S2), pp.482-486.

[2] H.J.Li, W.M.Kang and J.D.Su:Research on Ni-Base High-Temperature Alloy Processing. Cfhi Technology, Vol.(2017), No.02, pp.68-71.

[3] X.F.Zhao, Y.H.Wang, Y.Liu,X.L.Wang and Y.Wan:Ni-Base High-Temperature Alloy Cutting. Aeronautical Manufacturing Technology, Vol.(2010), No.11, pp.46-50.

[4] W.Y.Lv: Research on Short Arc Machining Technology. Nei Jiang Science \& Technology, Vol.34(2013), No.11, pp.116-117.

[5] J.Z.Zhang,J.P.Zhou,Y.Xu and X.F.Zhang:Experimental Study on Discharge Process of Short Arcing. Modern Manufacturing Engineering, Vol.(2013),No.11,pp.93-96.

[6] L.Yang and Z.Yang:Infrared Thermography Temperature Measurement Principle and Techn ology. First Edition(Science Press, BeiJing 2012 ):pp.1-2.

[7] Kyung-Hee Park, Jorge Olortegai-Yume. A study on droplets and their distribution for minimum quantity lubrication(MQL). International Journal of Machine Tools \& Manufacture, 2010, 50:824-833.

[8] D.M.Meng,M.J.Li and Y.L.Zhao:Experimental Study on Heat Treatment Process of Recycle Air Compressor Impeller Using 625 Alloy. Compressor Blower \& Fan Technology, Vol.(2011), No.05,pp.42 44. 